\title{
1 Study on the Influence of Anchorage Length and Pretension on the Working 2 Resistance of Rock Bolt Based on its Tensile Characteristics
}

\author{
3 Jucai Chang, ${ }^{1}$ Kai He, ${ }^{1}$ Dongdong Pang, ${ }^{1}$ Dong $\mathrm{Li},{ }^{1}$ Chuanming $\mathrm{Li},{ }^{1}$ and Bingjun $\mathrm{Sun}^{1}$ \\ ${ }^{1}$ Key Laboratory of Safe and Effective Coal Mining of the Ministry of Education, Anhui \\ University of Science and Technology, Huainan, 232001, China.
}

Correspondence should be addressed to Kai He: e_2718281828459045@foxmail.com

7

\begin{abstract}
In coal mining roadway support design, the working resistance of the rock bolt is the key factor affecting its support effect. Effective improvement of the working resistance is of great significance to roadway support. Based on the rock bolt's tensile characteristics and the mining roadway surrounding rock deformation, a mechanical model for calculating the working resistance of the rock bolt is established and solved. Taking the mining roadway of the 17102 (3) working face at the Panji $3^{\#}$ Well Coal Mine of China as a research object, with a quadrilateral section roadway, the influence of pretension and anchorage length on the working resistance of high-strength and ordinary rock bolts in the middle and corner of the roadway is studied. The results show that when the bolt is in the elastic stage, increasing the pretension and anchorage length can effectively improve the working resistance. When the bolt is in the yield and strain-strengthening stages, increasing the pretension and anchorage length cannot effectively improve the working resistance. The influence of pretension and anchorage length on the ordinary and high-strength bolts is similar. The ordinary bolt's working resistance is approximately $25 \mathrm{kN}$ less than that of the high-strength bolt. When pretension and anchorage length are considered separately, the best pretensions of the high-strength bolt in the middle of the roadway side and the roadway corner are 41.55 and $104.26 \mathrm{kN}$, respectively, and the best anchorage lengths are 1.54 and $2.12 \mathrm{~m}$, respectively. The best anchorage length of the ordinary bolt is the same as that of the high-strength bolt, and the best pretension for the ordinary bolt in the middle of the roadway side and at the roadway corner is 33.51 and $85.12 \mathrm{kN}$, respectively. The research results can provide a theoretical basis for supporting the design of quadrilateral mining roadways.
\end{abstract}

Keywords: Working resistance of rock bolt; Pretension; Anchorage length; Ordinary bolt; Highstrength bolt; Quadrilateral section roadway

\section{Introduction}

Deep mining is the norm in China. In a high-stress environment, the mining roadway often shows the characteristics of large deformation, so the deep mining roadway often requires higher support strength. As one of the main factors influencing support strength, effectively improving the working resistance of rock bolts has been a key research problem in mining engineering. To improve driving speed, mining roadway cross-sections are often rectangular, trapezoidal, or quadrilateral. However, the concentration of stress in the corners of quadrilateral cross sections is inevitable. The special stress distribution of the surrounding rock leads to different mechanical properties of the bolt in the middle of the roadway side and in the roadway corners.

As the key parameters of the bolt support design, anchorage length and pretension have a direct impact on the working resistance. Based on field engineering practice, physical experiment results, and theoretical reasoning analysis, many scholars at home and abroad have carried out in-depth research on anchorage length and pretension from different angles, and have achieved certain research results. However, these results are only applicable to circular, oval, and other regular cross section roadways. Owing to the large difference in the deformation and stress distribution of the surrounding rock between the quadrilateral cross section roadway and circular, elliptical, and other regular cross section roadways, many important research results are not suitable for quadrilateral cross section roadways. 
Regarding the research on the influence of pretension on the mechanical properties of rock bolts, some of the main research results are as follows: Wang et al. found that high bolt pretension force and mesh stiffness are of great significance to improve the bearing capacity of anchor mesh in coal, especially to reduce the degree of extrusion deformation and severe damage area [1]. Aziz et al. carried out a set of simple shear tests on fully sealed cable bolts using the newly developed integrated megabolt shear apparatus [2]. They found that increasing the pretension load reduces the peak shear load of the cable bolt. Ma et al. improved an analytical model to predict the shear stress of rock bolt by taking into account the pretension, axial forces, and interfacial bond stress [3]. Kocakaplan and Tassoulas examined the torsional response of a pretensioned bolt [4]. They showed how the pretension level affected the response of the bolt. Jalalifar et al. found that the bolt resistance to shear is influenced by the rock strength and the profile of the bolt, and that an increasing of the shearing load is contributed by the increasing of bolt pretension [5]. Jiang et al. found that the surrounding rock stress and pre-stress distribution of the arched roadway are better than those of the laddershaped roadway; therefore, the soft rock roadway should use the arched roadway and the pretension stress should be increased as much as possible under the premise that the anchorage performance of the bolts and cable bolts is guaranteed [6].

Regarding the research on the characteristics of the influence of the anchorage length on the mechanical properties of bolts, some of the main research results are as follows: Xu and Tian found that in the elastic stage of the bolt, an increase in the anchorage length contributes to an increase in the shear stress and an increase in the ultimate shear stress [7]. Using the distinct element method, Che et al. performed rock bolt pullout tests on soft rock. They found that the longer the rock bolt embedment length and the higher the confining pressure, the larger the peak load is [8]. Wang et al. found that when the anchorage length of the bolt is fixed, the effective compressive stress area in the surrounding rock of the non-anchored bolt increases with the increase of the pretension [9]. Chang and others defined the surrounding rock stability index and then studied the stability of the surrounding rock with different anchorage lengths. They found that, compared with the end-anchoring bolt support, the full-length anchoring bolt support reduces the area of instability to a greater extent [10]. Zou and Zhang studied the dynamic evolution characteristics of bond strength between bolt and rock mass under axial tensile load, and the mechanical behavior of fully grouted bolt considering the uneven surrounding rock stress around the bolt [11]. Wu et al. Studied the tensile behavior of rock mass reinforced by fully grouted bolt and unreinforced rock mass, and proposed an empirical method to predict the strength of rock mass reinforced by fully grouted bolt [12].

In conclusion, although many papers have rich research results, there are few papers considering the shape of the roadway cross section, and research on the influence of pretension and anchorage length on bolt anchorage mechanical characteristics is relatively small. In this paper, a mechanical model for calculating the bolt working resistance is proposed by referring to previous research results. Based on the bolt tensile curve and the surrounding rock displacement distribution, the mechanical model can comprehensively reflect the influence characteristics of pretension, anchorage length, roadway cross section shape, surrounding rock stress conditions, and surrounding rock lithology on the bolt working resistance. The analytical solution of the mechanical model is given by using the complex function method proposed by Muskhelishvili [13-18]. Taking the 17102 (3) working face mining roadway at the Pansan Coal Mine in the Huainan mining area as the engineering background, the influence of pretension and anchorage length on the working resistance of the high-strength bolt and the ordinary bolt in the middle of the roadway side and the roadway corner in the quadrilateral section roadway is studied. Finally, this paper summarizes the research results and provides conclusions.

\section{Mechanical model for calculating rock bolt working resistance}

A schematic diagram of the driving roadway is shown in Fig. 1. When the tunneling machine cuts out the complete roadway section, the rock bolt is installed immediately to support the roadway. Its position is shown as point A in Fig 1. Here, the surrounding rock has a small deformation under the support of the coal seam in front of it. Compared with the later deformation of the surrounding rock, the deformation can be 
ignored. When the bolt is far away from the driving working face, as shown in point $\mathrm{B}$, the bolt is affected by the surrounding rock deformation and the bolt axial force changes. The mechanical model for calculating the bolt working resistance can be established by analyzing the stress of the bolt at points A and B.

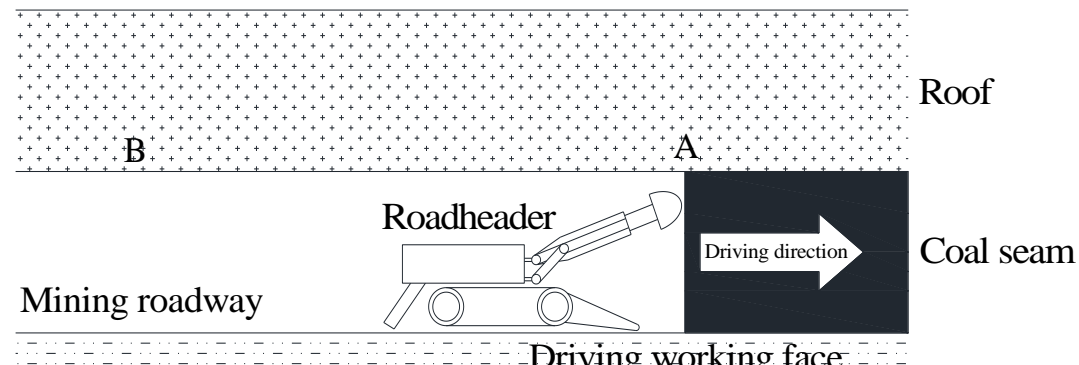

Driving working face

Floor

96

A stress diagram of the bolt is shown in Fig. 2. Here, $l_{s}$ represents the length of the borehole, $l_{t}$ represents the anchorage length, $T_{0}$ represents the pretension, $T$ represents the bolt working resistance, point $\mathrm{C}$ is at the edge of the anchorage agent, point $\mathrm{D}$ represents the borehole point of the rock wall, and $l_{1}, l_{2}, l_{3}$, and $l_{4}$ represent the non-anchorage lengths under different rock mass conditions.

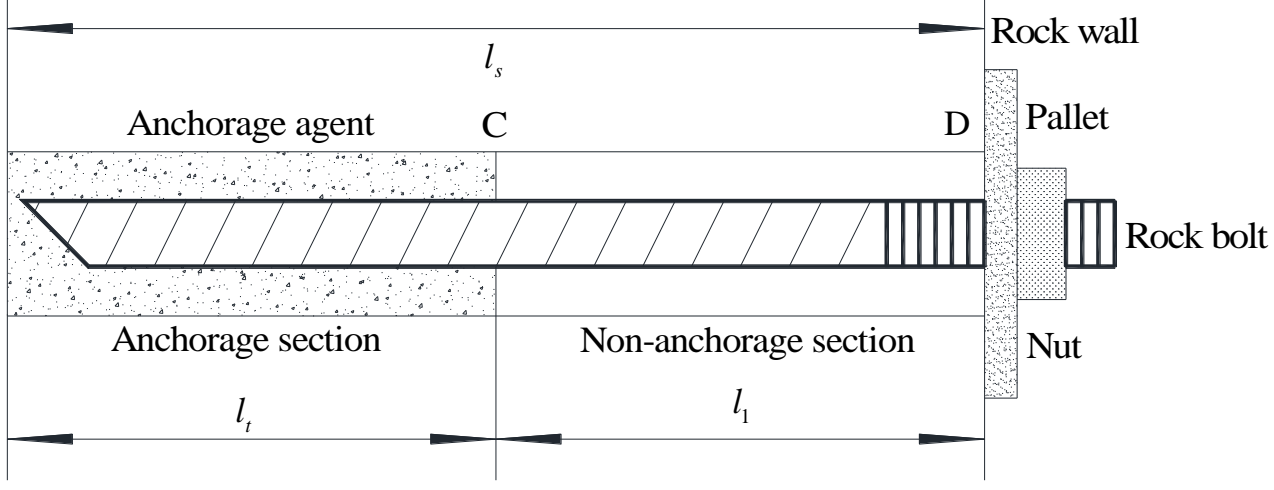

(a) Stress condition of bolt at point A without pretension

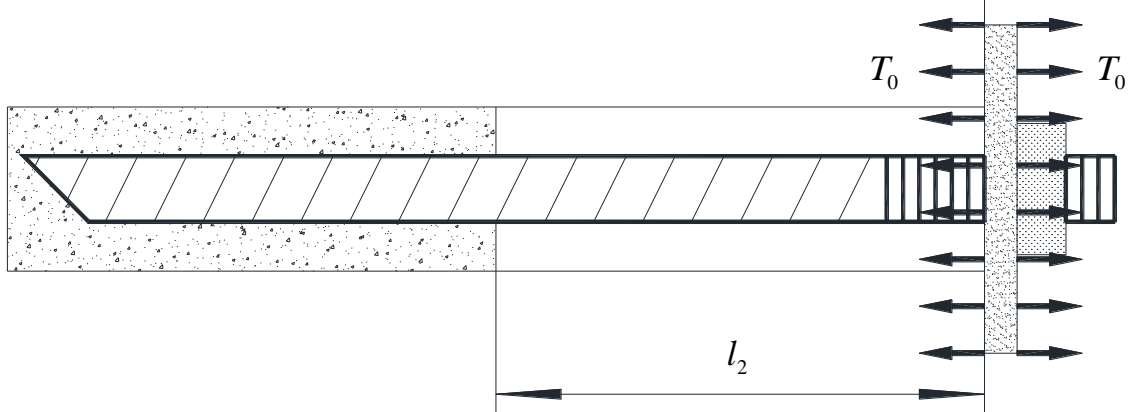

(b) Stress condition of bolt at point A with pretension $T_{0}$ 
106

107

108

109

110

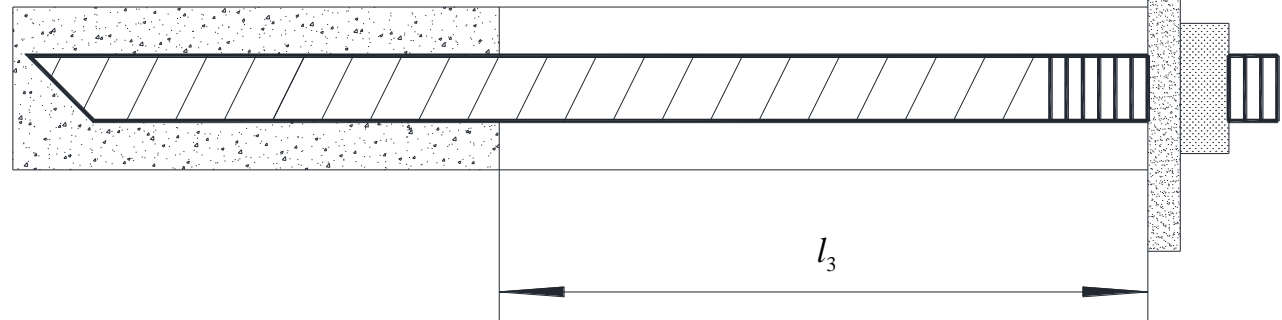

(c) Assuming that the bolt axial force is 0 , the stress condition of the bolt at point $\mathrm{B}$

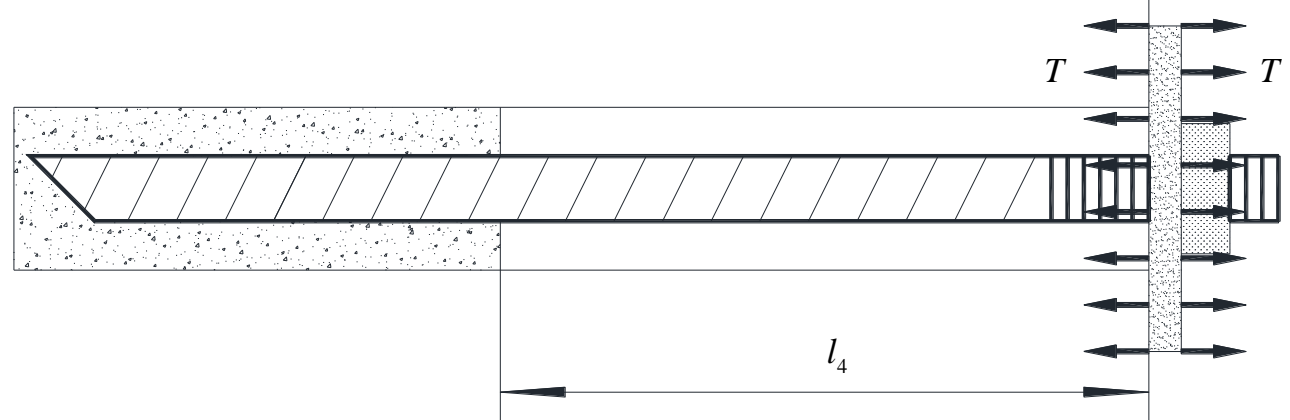

(d) Stress condition of the bolt at point B

Figure 2: Schematic diagram of bolt force

111 In the state shown in Fig. 2(a), the surrounding rock is not deformed, and the bolt is not preloaded; i.e., the

112 bolt axial force is 0. The rock mass state shown in Fig. 2(b) is based on the rock mass state shown in Fig.

113 2(a), and the pretension is applied to the bolt, i.e., the actual stress condition of the bolt at point A. In this

114 rock mass state, the pallet squeezes the rock wall and causes the rock wall to deform slightly, which leads to

115 the non-anchorage length $l_{1}$ to be smaller, and it is represented by $l_{2}$. Fig. 2(c) shows a hypothetical state

116 in which the surrounding rock deforms, but the axial force in the bolt is assumed to be 0 . The difference

117 between the state shown in Fig. 2(c) and that shown in Fig. 2(a) is only that the surrounding rock in the state

118 shown in Fig. 2(c) has been deformed. Owing to the deformation in the surrounding rock, the non-anchorage

119 length $l_{1}$ is usually lengthened, and the non-anchorage length is represented by $l_{3}$. Fig. 2(d) shows the actual

120 stress situation of the bolt at point $\mathrm{B}$, which can be obtained by the superposition of the rock mass state

121 shown in Figs. 2(b) and (c). Because of the surrounding rock deformation, the non-anchorage length $l_{1}$

122 becomes longer, and the non-anchorage length is represented by $l_{4}$. Because the non-anchorage length

123 changes from $l_{1}$ to $l_{4}$, the strain and axial force of the bolt increase.

124 When there is no stress in the surrounding rock and no pretension is applied to the bolt, the relationship between $l_{s}, l_{t}$, and $l_{1}$ is as shown in Fig. 2(a), as follows:

$$
l_{s}=l_{1}+l_{t} .
$$

When there is no deformation of the surrounding rock, the pallet will produce a squeezing force on the surrounding rock after the pretension is applied. This force is equal to the pretension, and the direction is opposite, as shown in Fig. 2(b). The function $g$ is used to represent the reduced part of the non-anchored section under the action of the squeezing force. The function $g$ is as follows: 


$$
g\left(T_{0}\right)=l_{1}-l_{2} .
$$

132 The function $f$ is used to represent the constitutive relation of the bolt. The function $f$ takes the bolt strain as the independent variable and the bolt axial force as the dependent variable. The following relationship exists:

$$
T_{0}=f\left(\varepsilon_{1}\right) .
$$

In Eq. (3), $\varepsilon_{1}$ represents the bolt strain before the deformation of the surrounding rock. It is assumed that the pallet does not exert pressure on the rock wall after the deformation of the surrounding rock, and the non-anchorage length is $l_{3}$, as shown in Fig. 2(c). When the surrounding rock is deformed, the bolt axial force changes and the bolt axial force is called the bolt working resistance $T$. When the pressure $T$ is applied to the rock wall by the pallet, the non-anchorage length is $l_{4}$, as shown in Fig. 2(d). In the same way as in 140 Eq. (2), it can be concluded that

$$
g(T)=l_{3}-l_{4} .
$$

142 Concurrently, the relationship between $T$ and the strain $\varepsilon_{2}$ of the bolt after the surrounding rock deformation 143 is as follows:

$$
T=f\left(\varepsilon_{2}\right) .
$$

145 According to the simple geometric relationship and the stress characteristics of the bolt in Figs. 2(b) and (d), 146 the following relationship can be obtained:

$$
\varepsilon_{2}=\frac{l_{4}}{l_{2}}+\varepsilon_{1}-1
$$

Combine Eqs. (1)-(6), organize, and simplify to obtain:

$$
T=f\left(\frac{l_{3}-g(T)}{l_{s}-l_{t}-g\left(T_{0}\right)}+f^{-1}\left(T_{0}\right)-1\right) .
$$

In Eq. (7), $l_{\mathrm{s}}$ and $l_{t}$ are known quantities; the constitutive relation $f$ can be obtained by the bolt tensile test; the function $g$ and $l_{3}$ can be obtained by the mechanical method. Then, by solving Eq. (7), the bolt working resistance $T$ can be obtained.

\subsection{Constitutive model of the bolt}

The bolt axial force $T^{\prime}$ is the main factor affecting the effect of the bolt support, but the bolt diameter has little effect on it. Therefore, the axial force-strain curve ( $T^{\prime}-\varepsilon$ curve) is used to describe the constitutive relationship of the bolt. The $T^{\prime}-\varepsilon$ curve can be divided into compression and tensile processes. The compression process can be divided into the compression elastic stage, compression yield stage, and compression strain-strengthening stage. The tensile process can be divided into the tensile elastic stage, tensile yield stage, tensile strain-strengthening stage, and fracture stage. The $T^{\prime}-\varepsilon$ curve is approximately an inclined straight line at the tensile and compression elastic stages. It is approximately a horizontal line in the compression and tensile yield stages. It is approximately an arc in the tensile and compression strainstrengthening stages. Moreover, the axial force is 0 in the fracture stage. The constitutive model is shown in Fig. 3.

In Fig. 3, $T_{b}$ represents the ultimate tensile strength, $T_{\mathrm{s}}$ represents the ultimate tensile yield strength, $T_{\mathrm{s}^{\prime}}$ represents the ultimate compression yield strength, $\varepsilon_{b}$ represents the ultimate tensile strain, $\varepsilon_{s^{\prime}}$ represents the ultimate compression strain, $\varepsilon_{s}{ }^{\prime}$ represents the starting point of the tensile strain-strengthening stage, and $\varepsilon_{s^{\prime}}$ represents the starting point of the compression strain-strengthening stage. The curve shapes of the tensile elastic stage, tensile yield stage, tensile strain-strengthening stage, and fracture stage were determined by bolt tensile tests. The bolt material has the following mechanical characteristics: the compression and tensile elastic stages, the compression and tensile yield stage are symmetrical to the origin. This characteristic can be expressed as follows: 


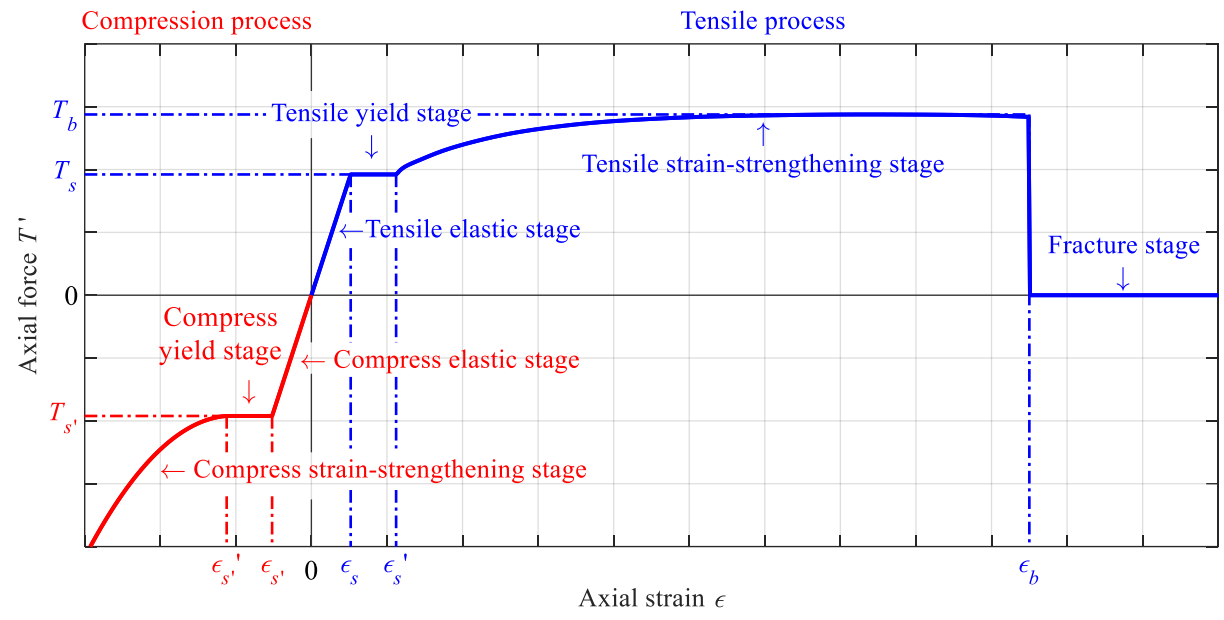

Figure 3: Constitutive model of the bolt

$$
\left\{\begin{array}{l}
T_{s}=T_{s^{\prime}}, \\
\varepsilon_{s}=\varepsilon_{s^{\prime}}, \\
\varepsilon_{s}{ }^{\prime}=\varepsilon_{s^{\prime}}{ }^{\prime} .
\end{array}\right.
$$

According to Eq. (8), the compression elastic stage and compression yield stage of the bolt can be supplemented by the tensile elastic and yield stages. Under actual working conditions, compression deformation usually does not occur, even if compression deformation occurs, and the amount of compression deformation is also very small. Therefore, the compression strain-strengthening stage was not considered. The function $f$ is used to represent the constitutive relation of the bolt, as shown in Fig. 3. The function $f$ is as follows:

$$
T^{\prime}=f(\varepsilon)
$$

In Eq. (9), $\varepsilon$ is the axial strain of the bolt. The piecewise function and Fourier series can be used to fit Eq. (9).

\subsection{Solution of function $g$}

The rock wall is simplified as a semi-infinite body, and the force of the pallet on the surrounding rock is simplified as a uniform load in the circular area. To simplify the calculation process, it is assumed that the pallet has no shear effect on the rock wall, and the force of the pallet on the rock wall is shown in Fig. 4.

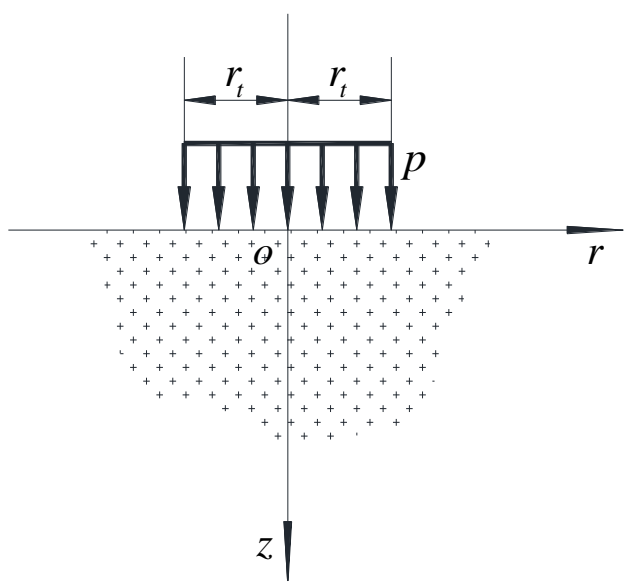


190 In Fig. 4, $r_{t}$ represents the radius of the equivalent circle of the pallet area and $p$ represents the equivalent 191 load of the working resistance. The calculation method is as follows:

$$
\left\{\begin{array}{l}
r_{t}=\sqrt{\frac{S}{\pi}} \\
p=\frac{T}{S} .
\end{array}\right.
$$

In Eq. (10), $S$ represents the pallet area. The displacement in the z-direction of the mechanical model shown

194 in Fig. 4 is as follows:

$$
u_{z}(r, z)=\frac{p r_{t}}{G} \int_{0}^{+\infty}\left(\frac{1-v}{\kappa}+\frac{z}{2}\right) J_{0}(\kappa r) J_{1}\left(\kappa r_{t}\right) e^{-\kappa z} \mathrm{~d} \kappa .
$$

In Eq. (11), $G$ represents the shear modulus of the surrounding rock; $v$ represents the Poisson's ratio of the surrounding rock; functions $J_{0}$ and $J_{1}$ represent the Bessel function of the first kind with orders 0 and 1 , respectively; additionally, $\kappa$ and represents the integral variable. According to simple geometric relations,

$$
g(T)=u_{z}\left(0, l_{1}\right)-u_{z}(0,0) .
$$

By substituting Eqs. (1), (10), and (11) into Eq. (12), and simplifying, we obtain the following results:

$$
g(T)=\frac{T}{G \sqrt{\pi S}} \cdot \int_{0}^{+\infty}\left\{2(v-1)-\left[2(v-1)+\kappa\left(l_{t}-l_{s}\right)\right] \cdot e^{\kappa\left(l_{t}-l_{s}\right)}\right\} \cdot \frac{J_{1}\left(\kappa r_{t}\right)}{2 \kappa} \cdot \mathrm{d} \kappa .
$$

It can be seen from Eq. (13) that the function value $g(T)$ is positively proportional to the working resistance $T$.

\subsection{Calculation method of non-anchorage length $l_{3}$}

The deep underground roadway can be regarded as an opening in an infinite rock mass. The surrounding rock pressure conditions are expressed by the vertical pressure $\sigma_{V}$, horizontal pressure $\sigma_{H}$, and shear stress

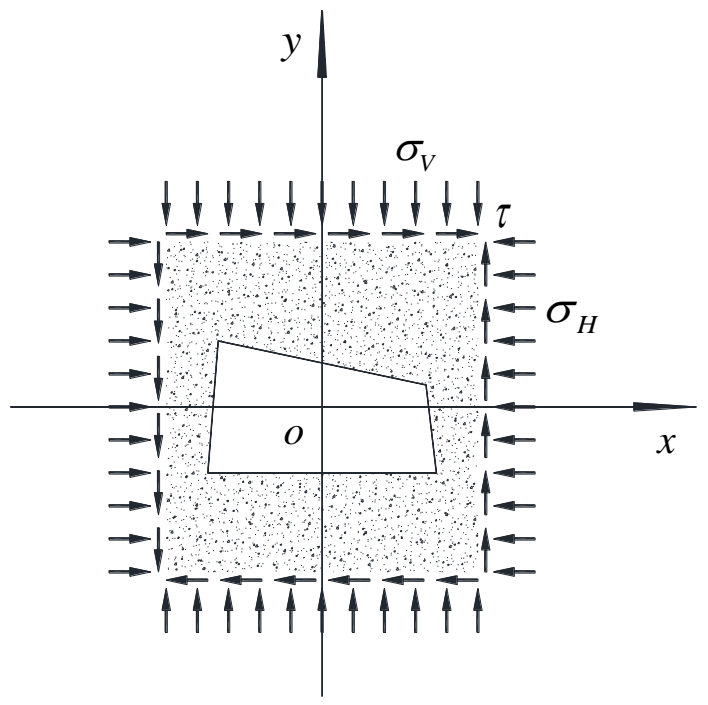

The complex variable function method proposed by Muskhelishvili is used to solve the displacement distribution law [13]. The displacement distribution of the surrounding rock in the quadrilateral roadway belongs to the plane strain problem. The displacement of the surrounding rock can be determined by two complex functions $\varphi(z)$ and $\psi(z)$. They take the following forms: 


$$
\left\{\begin{array}{l}
\varphi(z)=\frac{\sigma_{V}+\sigma_{H}}{4} \cdot \omega(\xi)+\varphi_{0}(\xi), \\
\psi(z)=\sqrt{\left(\sigma_{V}-\sigma_{H}\right)^{2}+4 \tau^{2}} \cdot \frac{e^{2 \alpha i} \omega(\xi)}{4}+\psi_{0}(\xi) .
\end{array}\right.
$$

215 In Eq. (14), the complex functions $\varphi_{0}(\xi)$ and $\psi_{0}(\xi)$ represent analytic functions satisfying the Cauchy-

216 Riemann condition, and they can be expanded into a Taylor series; the value of $\alpha$ is shown in Eq. (18); the 217 function $\omega(\xi)$ is a conformal mapping function; $\xi=\rho \cdot e^{i \theta}$ is a complex variable.

$$
\alpha=\arctan \left(\frac{\sigma_{V}-\sigma_{H}+\sqrt{\left(\sigma_{V}-\sigma_{H}\right)^{2}+4 \tau^{2}}}{2 \tau}\right)
$$

The conformal mapping function can be obtained according to the algorithm proposed in [19-24]. The analytic functions $\varphi_{0}(\xi)$ and $\psi_{0}(\xi)$ can be obtained by boundary conditions [13]. The analytic solutions of the complex functions $\varphi(z)$ and $\psi(z)$ can be obtained by substituting the analytic functions $\varphi_{0}(\xi)$ and $\psi_{0}(\xi)$ into Eq. (14). According to the complex functions $\varphi(z)$ and $\psi(z)$, the displacement distribution can be obtained as follows:

$$
u_{\rho}+i u_{\theta}=\frac{e^{-\theta i} \cdot \overline{\omega^{\prime}(\xi)}}{2 G\left|\omega^{\prime}(\xi)\right|} \cdot\left((3-4 v) \varphi(\xi)-\frac{\omega(\xi)}{\overline{\omega^{\prime}(\xi)}} \overline{\varphi^{\prime}(\xi)}-\overline{\psi(\xi)}\right) .
$$

225

226

227

228

229

The displacement distributions $u_{\rho}$ and $u_{\theta}$ are based on the curvilinear coordinate system determined by the conformal mapping function $\omega(\xi)$. The displacement distribution in the curvilinear coordinate system needs to be transformed into a rectangular coordinate system. From differential geometry, the directional cosine matrix from the curvilinear coordinate system to the rectangular coordinate system can be obtained as follows:

$$
\mathbf{U}=\left[\frac{\left[\begin{array}{ll}
\frac{\partial x}{\partial \rho} & \frac{\partial y}{\partial \rho}
\end{array}\right]^{\mathrm{T}}}{\sqrt{\left(\frac{\partial x}{\partial \rho}\right)^{2}+\left(\frac{\partial y}{\partial \rho}\right)^{2}}} \frac{\left[\begin{array}{ll}
\frac{\partial x}{\partial \theta} & \frac{\partial x}{\partial \theta}
\end{array}\right]^{\mathrm{T}}}{\sqrt{\left(\frac{\partial x}{\partial \theta}\right)^{2}+\left(\frac{\partial y}{\partial \theta}\right)^{2}}}\right]^{\mathrm{T}}
$$

The displacement distributions in the rectangular and curved coordinate systems can be converted as follows:

$$
\left[\begin{array}{l}
u_{x} \\
u_{y}
\end{array}\right]=\mathbf{U} \cdot\left[\begin{array}{l}
u_{\rho} \\
u_{\theta}
\end{array}\right] .
$$

Using Eq. (18), the non-anchorage length $l_{3}$ can be obtained according to a simple geometric relationship, as follows:

$$
l_{3}=l_{1}+\sqrt{\left[u_{x}\left(\rho_{\mathrm{C}}, \theta_{\mathrm{C}}\right)-u_{x}\left(\rho_{\mathrm{D}}, \theta_{\mathrm{D}}\right)\right]^{2}+\left[u_{y}\left(\rho_{\mathrm{C}}, \theta_{\mathrm{C}}\right)-u_{y}\left(\rho_{\mathrm{D}}, \theta_{\mathrm{D}}\right)\right]^{2}} .
$$

In Eq. (19), $\left(\rho_{\mathrm{C}}, \theta_{\mathrm{C}}\right)$ and $\left(\rho_{\mathrm{D}}, \theta_{\mathrm{D}}\right)$ represent the coordinates of points $\mathrm{C}$ and $\mathrm{D}$ in the $\xi$ plane, respectively.

\section{Results and Discussion}

Based on the mining roadway of the 17102 (3) working face in the Pansan Coal Mine of the Huainan Mining Group as the engineering background, the influence of pretension and anchorage length on the working resistance is studied. The cross section of the mining roadway is quadrilateral, and the rock bolt support scheme is adopted, as shown in Fig. 6. The main bolt-supporting parameters are as follows: five bolts are installed on the high side with a spacing of $800 \mathrm{~mm}$; four bolts are installed at the low side with a spacing of $800 \mathrm{~mm}$; seven bolts are installed on the roof with a spacing of $750 \mathrm{~mm}$. All the bolts are high-strength bolts 
with a length of $2500 \mathrm{~mm}$ and a diameter of $22 \mathrm{~mm}$. Concurrently, other supporting materials such as anchor cables, anchor nets, and steel belts are used. Taking bolt A as an example, the influence of pretension and anchorage length on the bolt in the middle of the roadway side is studied. Taking anchor bolt B as an example, the influence of pretension and anchorage length on the bolt in the roadway corner is studied.

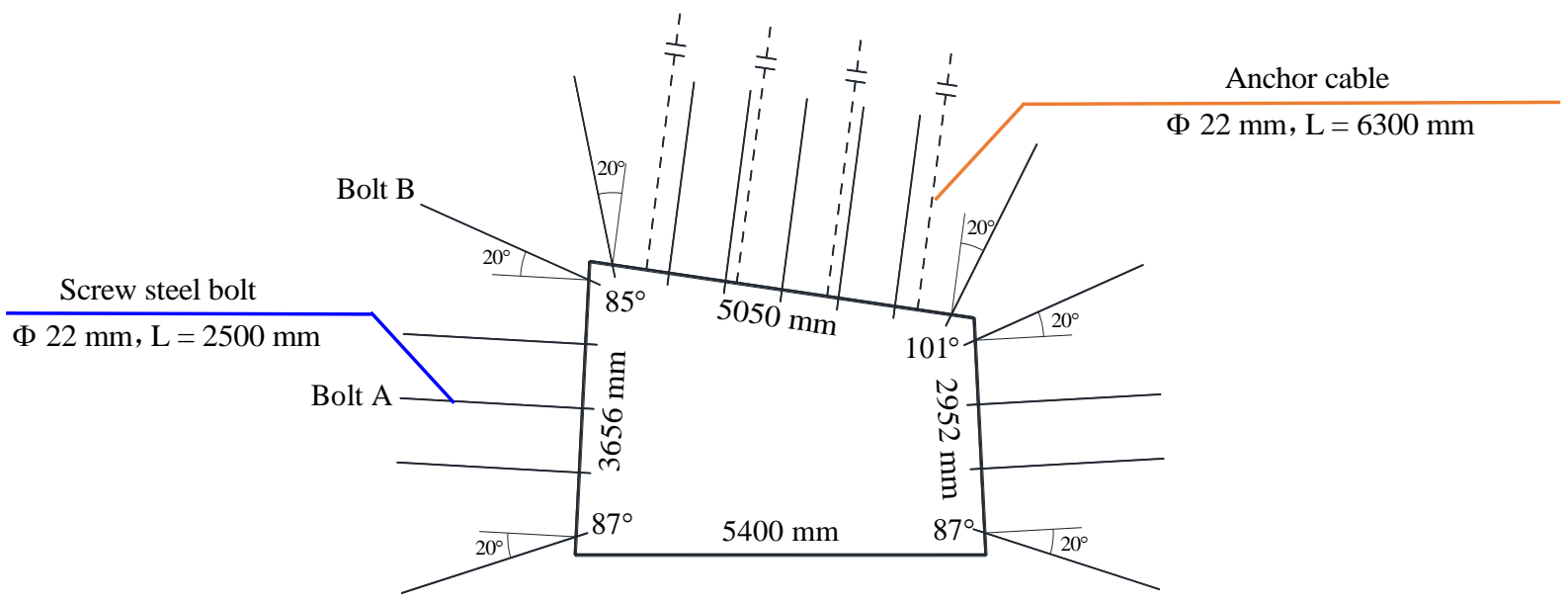

According to the in-situ stress test results, the vertical stress $\sigma_{V}$ is $16.8 \mathrm{MPa}$, the horizontal stress $\sigma_{H}$ is 13.3 MPa, and the shear stress $\tau$ is $0.5 \mathrm{MPa}$. The roof and floor of the 17102 (3) working face are both composed of mudstone and sandy mudstone, which have mechanical properties similar to those of the coal seam and are combined. According to the results of the rock mechanics test, the shear modulus of the surrounding rock $G$ is $1.22 \mathrm{GPa}$ and the Poisson's ratio $v$ is 0.23 .

\subsection{Constitutive model of the high-strength bolt and the ordinary bolt}

Taking the high-strength and ordinary bolts as the test samples, the tensile test of the bolt was carried out using the WAW-2000 universal testing machine, and the $T^{\prime}-\varepsilon$ curve was obtained. The diameter of the high-strength bolt is $22 \mathrm{~mm}$, and that of the ordinary bolt is $20 \mathrm{~mm}$. Six high-strength bolts and six ordinary anchors were selected. To facilitate the test experiment, a total of 12 specimens were randomly cut from each bolt with a length of $750 \mathrm{~mm}$. The tensile test of the bolts is shown in Fig. 7, and the broken bolts are shown in Fig. 8.

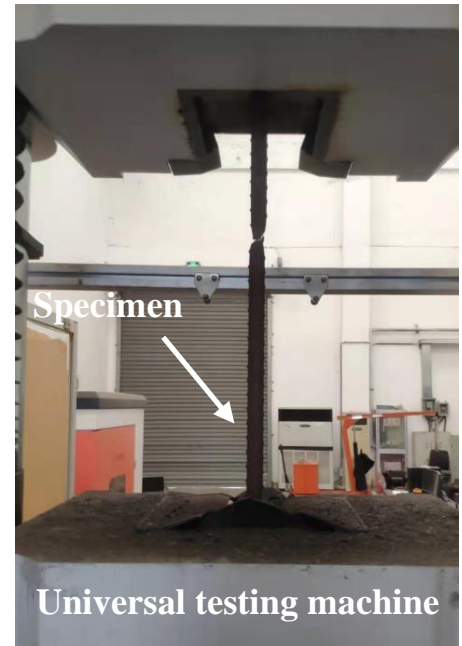

Figure 7: Tensile test of bolts

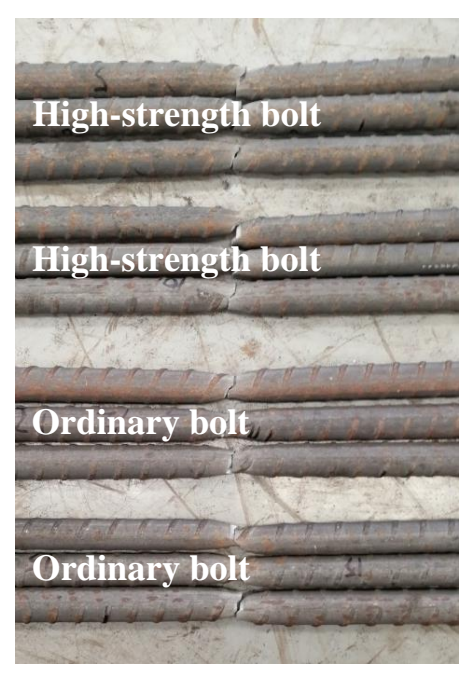

Figure 8: Picture of broken bolts 
The fitting results of the $T^{\prime}-\varepsilon$ curve for all specimens and the constitutive model are shown in Fig. 9, and the key parameters of the tensile curve for all specimens are shown in Table 1. It can be seen from Fig. 9 that the $T^{\prime}-\varepsilon$ curve trend for all bolt specimens is the same, and there is no abnormal change. Regardless of the necking stage of the bolt, the bolt is broken when it enters the necking stage. The constitutive model of the bolt in the tensile stage can be fitted from the $T^{\prime}-\varepsilon$ curve obtained from the test. The constitutive model of the bolt in the compression stage can be calculated according to Eq. (8). The elastic stage of the bolt is fitted by an inclined straight line, the yield stage of the bolt is fitted by a horizontal line, and the strainstrengthening stage of the bolt is fitted by a second-order Fourier series. The fitting results of the constitutive model of the high-strength bolt are shown in Eq. (20), and that of the ordinary bolt are shown in Eq. (21).

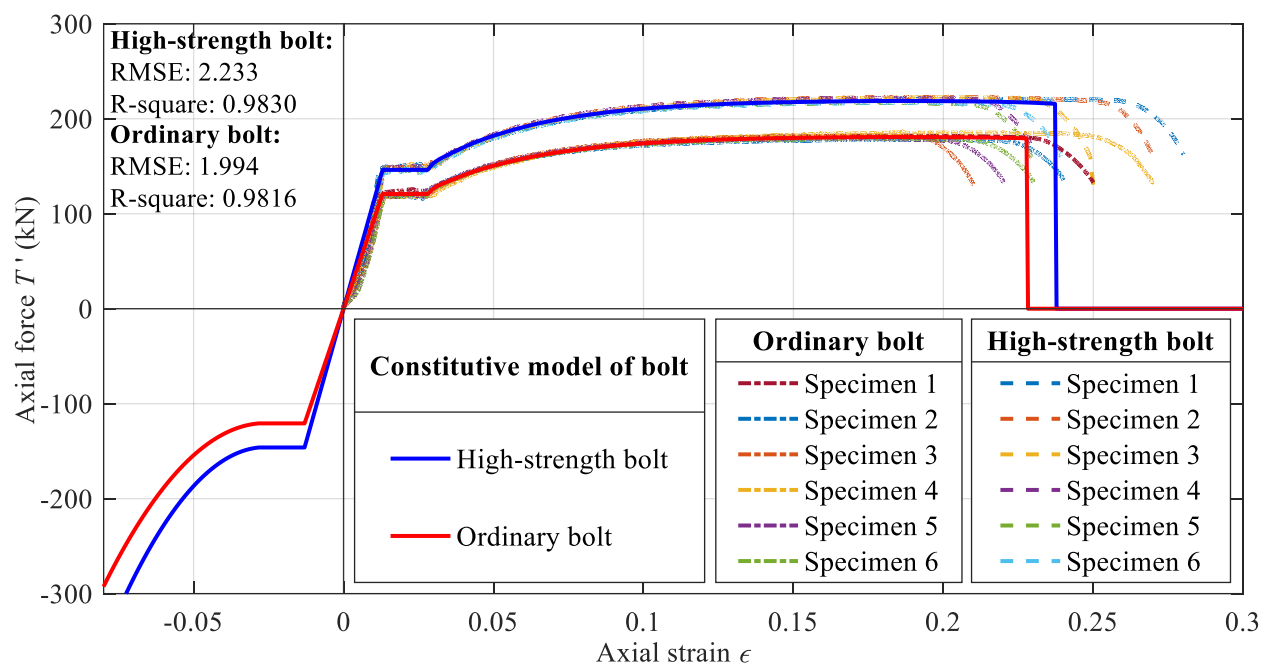

Figure 9: Test results and bolt constitutive model

Table 1: Tensile test results of specimens

\begin{tabular}{ccccccc}
\hline Bolts & Specimens & $T_{s} / \mathrm{kN}$ & $T_{b} / \mathrm{kN}$ & $\mathcal{E}_{s}$ & $\mathcal{E}_{s}{ }^{\prime}$ & $\varepsilon_{b}$ \\
\hline \multirow{5}{*}{ High-strength bolt } & 1 & 148.2 & 219.2 & 0.01240 & 0.02160 & 0.2582 \\
& 2 & 147.7 & 216.3 & 0.01398 & 0.02085 & 0.2539 \\
& 3 & 149.5 & 222.1 & 0.01418 & 0.02170 & 0.2293 \\
& 4 & 145.6 & 220.6 & 0.01376 & 0.02040 & 0.2084 \\
& 5 & 140.8 & 213.7 & 0.01298 & 0.01866 & 0.2117 \\
Ordinary bolt & 6 & 145.0 & 213.7 & 0.01355 & 0.01990 & 0.2209 \\
& Average & 146.1 & 217.6 & 0.01348 & 0.02052 & 0.2304 \\
& 1 & 123.7 & 180.3 & 0.01281 & 0.02801 & 0.2278 \\
& 2 & 118.5 & 176.8 & 0.01183 & 0.01480 & 0.2182 \\
& 4 & 119.7 & 181.2 & 0.01388 & 0.01723 & 0.1939 \\
& 5 & 119.0 & 182.9 & 0.01369 & 0.01881 & 0.2484 \\
& 6 & 119.5 & 177.5 & 0.01334 & 0.01487 & 0.1999 \\
& Average & 120.0 & 177.5 & 0.01395 & 0.01607 & 0.2090 \\
& 120.1 & 179.4 & 0.01325 & 0.01830 & 0.2162 \\
\hline
\end{tabular}

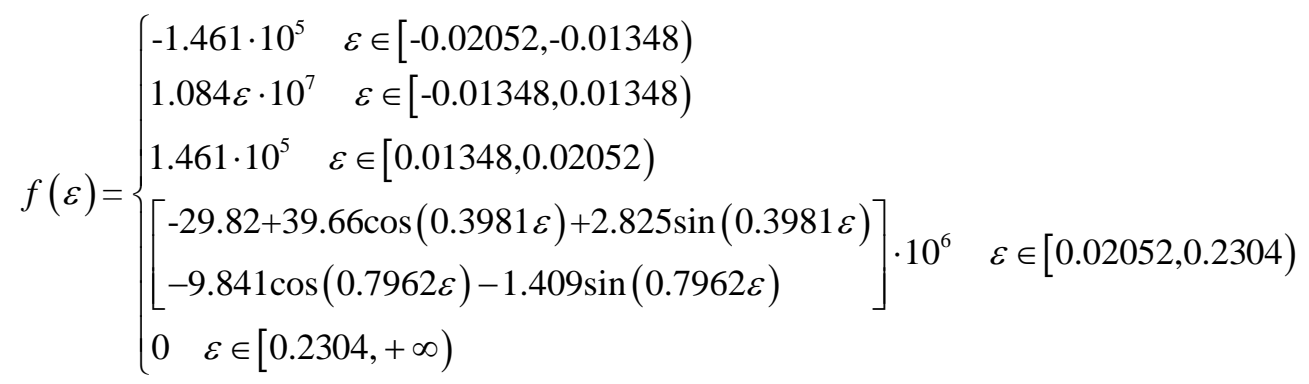




$$
f(\varepsilon)=\left\{\begin{array}{l}
-1.201 \cdot 10^{5} \quad \varepsilon \in[-0.01830,-0.01325) \\
9.064 \varepsilon \cdot 10^{6} \quad \varepsilon \in[-0.01325,0.01325) \\
1.201 \cdot 10^{5} \quad \varepsilon \in[0.01325,0.01830) \\
{\left[\begin{array}{ll}
-51.71+68.91 \cos (0.1893 \varepsilon)+2.341 \sin (0.1893 \varepsilon) \\
-17.20 \cos (0.3786 \varepsilon)-1.170 \sin (0.3786 \varepsilon)
\end{array}\right] \cdot 10^{7} \quad \varepsilon \in[0.01830,0.2162)} \\
0 \quad \varepsilon \in[0.2162,+\infty)
\end{array}\right.
$$

The root mean squared error (RMSE) of the constitutive models (20) and (21) are 2.233 and 1.994, respectively, and the coefficients of determination (R-square) are 0.9830 and 0.9816 , respectively. The RMSE of the constitutive models (20) and (21) is relatively small, and the R-square is close to one, showing that the fitting effect of the constitutive models (20) and (21) is good, which can be used for follow-up research.

\subsection{Influence of $T_{0}$ and $l_{t}$ on the high-strength bolt's $T$ in the middle of the roadway side}

According to the support scheme and geological conditions, taking bolt $\mathrm{A}$ as the research object, the variation curve of the working resistance $T$ of the high-strength bolt in the middle of the roadway side with an increase in the anchorage length $l_{t}$ is obtained when the pretension $T_{0}$ is different, as shown in Fig. 10. To facilitate the later comparative analysis, the key points of the working resistance curve are marked in Fig. 10. The pretension $T_{0}$ and anchorage length $l_{t}$ at the key points are listed in Table 2.
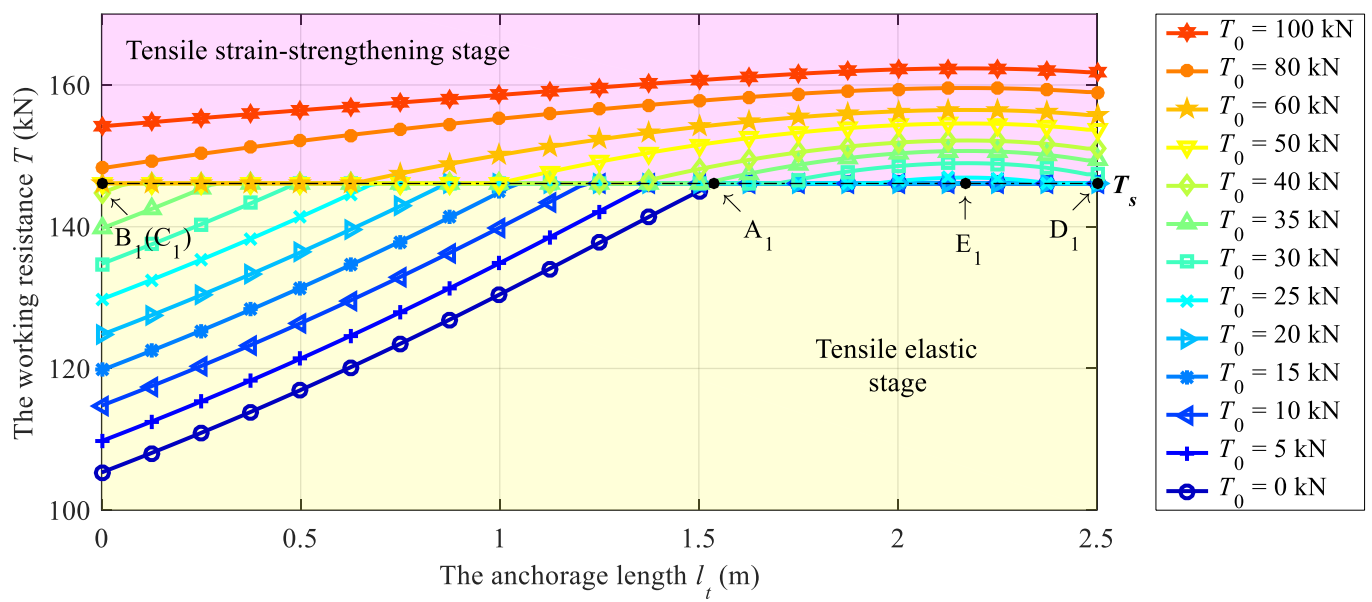

Figure 10: Curves of the high-strength bolt's $T$ in the middle of roadway side with different $T_{0}$ values

Table 2: Parameters of the key points shown in Fig. 9

\begin{tabular}{cccccc}
\hline Parameters & $\mathrm{A}_{1}$ & $\mathrm{~B}_{1}$ & $\mathrm{C}_{1}$ & $\mathrm{D}_{1}$ & $\mathrm{E}_{1}$ \\
\hline$T_{0} / \mathrm{kN}$ & 146.1 & 41.55 & 75.23 & 27.96 & 23.39 \\
$l_{s} / \mathrm{m}$ & 1.54 & 0 & 0 & 2.5 & 2.17 \\
\hline
\end{tabular}

In Fig. 10, the working resistance in the light yellow area is less than the ultimate yield strength $T_{s}$, and the bolt is in the elastic stage. In the light pink area, the working resistance is greater than the ultimate yield strength $T_{s}$, and the bolt is in the strain-strengthening stage. According to the change in the bolt stage with anchorage length, the working resistance curves under different pretension conditions can be divided into five categories. After calculation, the pretension ranges of different types of working resistance curves, the change of bolt stage with the increase in anchorage length, and the example curve in Fig. 10 are shown in Table 3. 
Fig. 10 shows that the variation rules of the working resistance curves of different types are the same in the elastic, yield, and strain-strengthening stages. In the elastic stage, the working resistance increases linearly and the working resistance curves under different pretensions are mostly parallel. Moreover, in the elastic stage, the growth rate of the working resistance mostly remains unchanged under different pretension conditions. In the yield stage, the working resistance does not change. Notably, the working resistance cannot be improved by increasing the anchorage length in the yield stage. In the strain-strengthening stage, the working resistance first increases and then decreases. When the anchorage length is approximately $2.2 \mathrm{~m}$, the working resistance reaches its maximum value. The overall variation range of the working resistance is relatively small in the strain-strengthening stage. This shows that increasing the anchorage length cannot effectively improve the working resistance in the yield stage. When the anchorage length is larger than point $\mathrm{A}_{1}$, i.e., $l_{t}>1.54 \mathrm{~m}$, the bolt is in the yield stage or the strain-strengthening stage, regardless of the pretension value. With an increase in the anchorage length, the working resistance increases slowly, and a continuous increase in the anchorage length cannot effectively improve the working resistance. Therefore, the best anchorage length of the high-strength bolt in the middle of the roadway side is $1.54 \mathrm{~m}$ without considering the pretension.

Table 3: High-strength bolt's $T$-curve classification with different pretensions in the middle of roadway side

\begin{tabular}{cccc}
\hline Curve categories & Pretension ranges & Stages of bolts with different anchorage lengths & Examples \\
\hline I & $0-23.39 \mathrm{kN}$ & Elastic stage $\rightarrow$ Yield stage & $0-20 \mathrm{kN}$ \\
II & $23.39-27.96 \mathrm{kN}$ & Elastic stage $\rightarrow$ Yield stage $\rightarrow$ Strain-strengthening & $25 \mathrm{kN}$ \\
stage $\rightarrow$ Yield stage & Elastic stage $\rightarrow$ Yield stage $\rightarrow$ Strain-strengthening & $30-40 \mathrm{kN}$ \\
III & $27.96-41.55 \mathrm{kN}$ & stage & 50 and $60 \mathrm{kN}$ \\
VI & $41.55-75.23 \mathrm{kN}$ & Yield stage $\rightarrow$ Strain-strengthening stage & 80 and $100 \mathrm{kN}$ \\
V & $>75.23 \mathrm{kN}$ & Strain-strengthening stage &
\end{tabular}

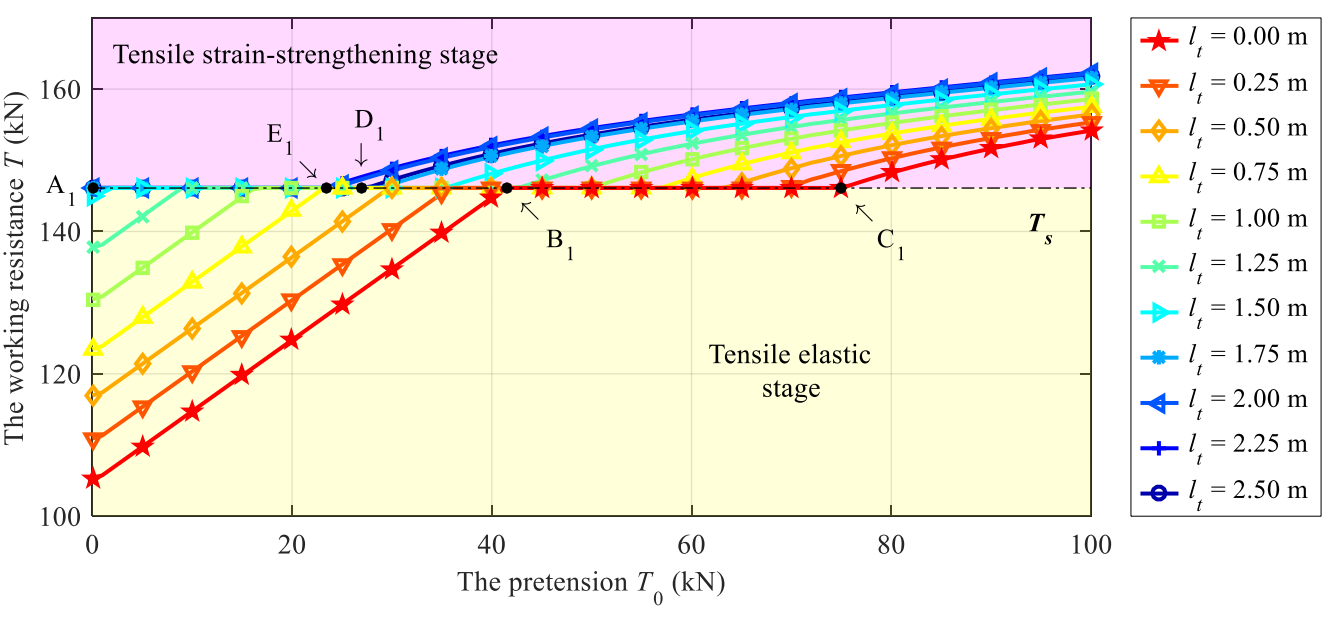
317 When the anchorage length $l_{t}$ is different, the change trend of the working resistance with the increase in
318 pretension is shown in Fig. 11. It can be seen from Fig. 11 that when the anchorage length is different, the 319 working resistance increases monotonically with the increase in pretension. According to the change in the bolt stage, the working resistance curves can be divided into two categories. After calculation, the anchorage length range of the different types of working resistance curve, the change of bolt stage with the increase in pretension, and the example curve in Fig. 11 are shown in Table 4. 


\begin{tabular}{cccc}
\hline Curve categories & Anchorage lengths & Stages of bolts with different pretensions & Examples \\
\hline I & $0-1.54 \mathrm{~m}$ & Elastic stage $\rightarrow$ Yield stage $\rightarrow$ Strain-strengthening & $0-1.50 \mathrm{~m}$ \\
stage & $>1.54 \mathrm{~m}$ & Yield stage $\rightarrow$ Strain-strengthening stage & $1.75-2.50 \mathrm{~m}$ \\
\hline
\end{tabular}

Fig. 11 shows that the variation rules of the working resistance curves of different types are the same in the elastic, yield, and strain-strengthening stages. In the elastic stage, the working resistance increases linearly with increasing pretension, and the working resistance curves with different anchorage lengths are mostly parallel. The results show that in the elastic stage, the working resistance growth rate with increasing pretension is fundamentally the same under the condition of different anchorage lengths. In the yield stage, the working resistance does not change. Notably, in the yield stage, increasing the pretension cannot improve the working resistance. When the bolt is in the strain-strengthening stage, the working resistance increases monotonically with increasing pretension, but the increase range is relatively small. When the pretension is greater than point $\mathrm{B}_{1}$, i.e., $T_{0}>41.55 \mathrm{kN}$, regardless of the anchorage length, the bolt is in the yield stage or strain-strengthening stage. With increasing pretension, the working resistance increases slowly, and the effect of the continuously increasing pretension on improving the working resistance is limited. Therefore, without considering the anchorage length, the best pretension for the high-strength bolt in the middle of the roadway side is $41.55 \mathrm{kN}$.

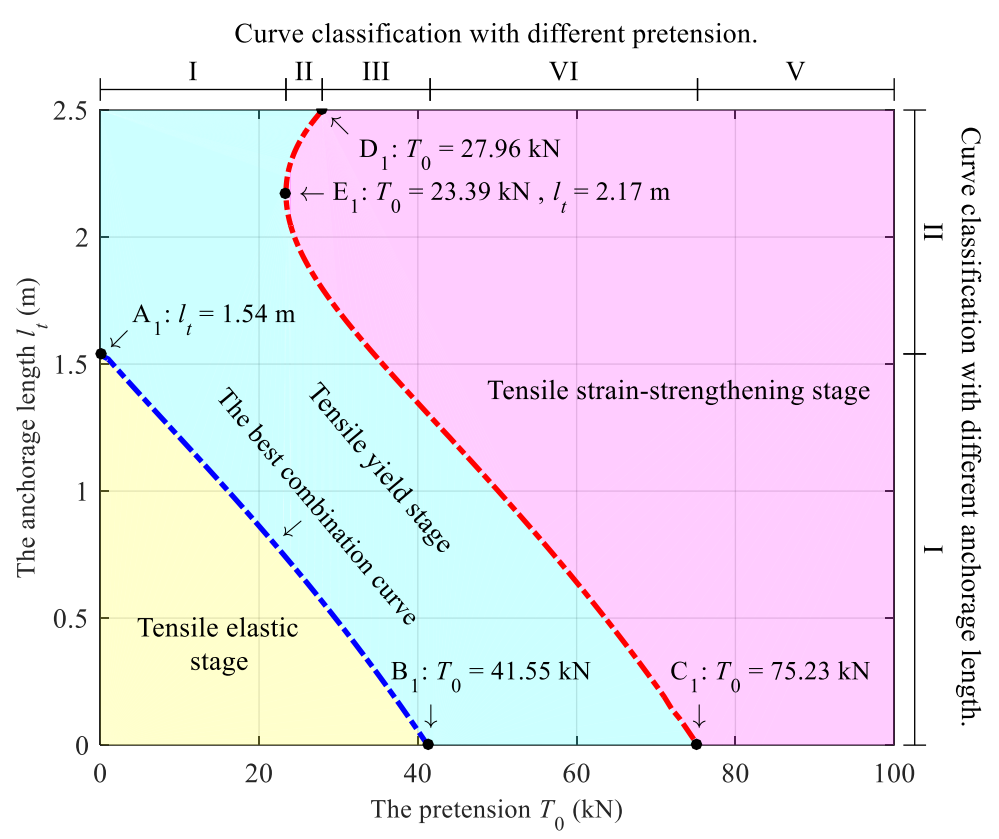

Figure 12: High-strength bolt stage under different combinations of $T_{0}$ and $l_{t}$ in the middle of roadway side

Under the combination of the pretension $T_{0}$ and anchorage length $l_{t}$, the stage of the high-strength bolt in the middle of the roadway side is shown in Fig. 12. Concurrently, the positions of the working resistance curves for different types are indicated in Fig. 12. It can be seen from the analysis in Figs. 10 and 11 that when the bolt enters the yield and strain-strengthening stages, the effect of increasing pretension and anchorage length on improving the working resistance is not evident. Considering the relationship between construction cost and the supporting effect, the boundary line between the elastic stage and the yield stage can be used as the best combination curve for the pretension and anchorage length. It can be seen from Fig. 12 that the best combination curve of pretension and anchorage length is approximately a straight line. 


\subsection{Influence of pretension and anchorage length on the working resistance of the high- strength bolt at the roadway corner}

Taking bolt $\mathrm{B}$ as the research object, the variation curve of the working resistance $T$ of the high-strength bolt at the roadway corner with an increase in the anchorage length $l_{t}$ is obtained when the pretension $T_{0}$ is different, as shown in Fig. 13. To facilitate the comparative analysis, the key points of the working resistance curve are marked in Fig. 13. The pretensions $T_{0}$ and anchorage lengths $l_{t}$ at the key points are listed in Table 5 .
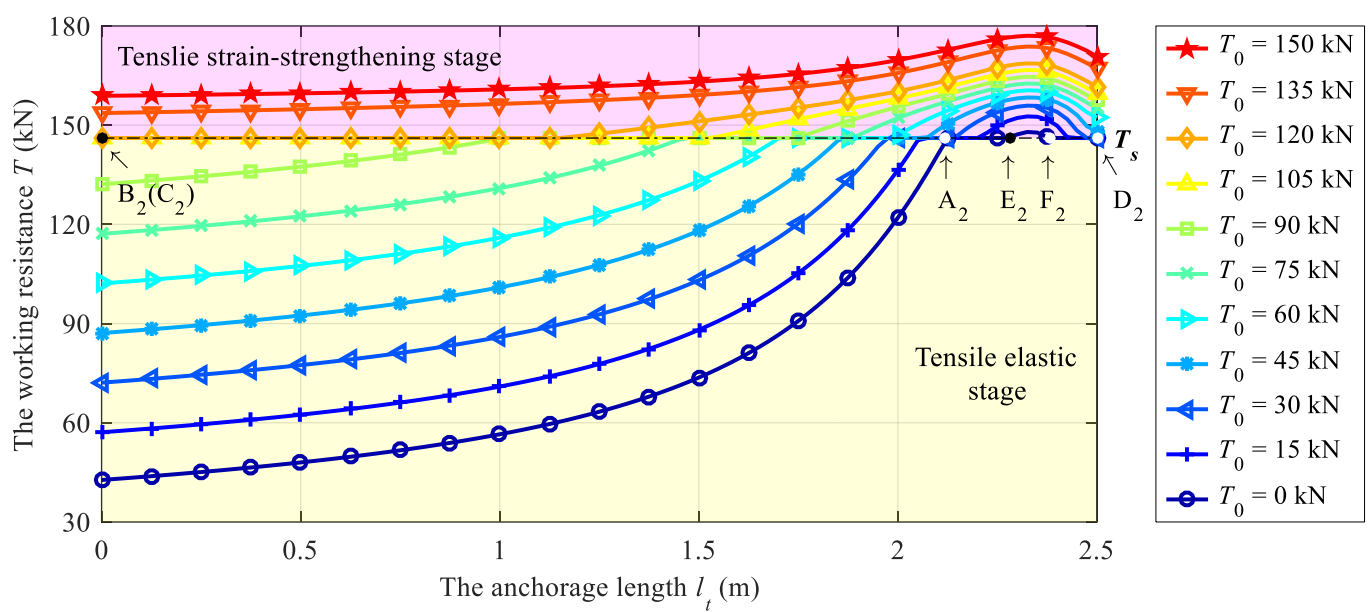

Figure 13: Curves of the high-strength bolt's $T$ on the roadway corner with different $T_{0}$ values

Table 5: Parameters of the key points in Fig. 13

\begin{tabular}{ccccccc}
\hline Parameters & $\mathrm{A}_{2}$ & $\mathrm{~B}_{2}$ & $\mathrm{C}_{2}$ & $\mathrm{D}_{2}$ & $\mathrm{E}_{2}$ & $\mathrm{~F}_{2}$ \\
\hline$T_{0} / \mathrm{kN}$ & 0 & 104.26 & 133.72 & 47.43 & 0 & 0 \\
$l_{s} / \mathrm{m}$ & 2.12 & 0 & 0 & 2.5 & 2.28 & 2.38 \\
\hline
\end{tabular}

Fig. 13 shows that under the different pretension conditions, the variation trend of the working resistance at the roadway corner is mostly the same as that in the middle of the roadway side. According to the change in the bolt stage with increasing anchorage length, the working resistance curves under the different pretension conditions can be divided into four categories. The pretension range and the change in the bolt stage with the increase in the anchorage length and the example curves in Fig. 13 are shown in Table 6.

Table 6: High-strength bolt's $T$ curve classification with different pretensions at the roadway corner

\begin{tabular}{cccc}
\hline Curve categories & Pretension ranges & Stages of bolts with different anchorage lengths & Examples \\
\hline I & $0-47.43 \mathrm{kN}$ & Elastic stage $\rightarrow$ Yield stage $\rightarrow$ Strain-strengthening \\
stage $\rightarrow$ Yield stage & $0-45 \mathrm{kN}$ \\
II & $47.73-104.26 \mathrm{kN}$ & Elastic stage $\rightarrow$ Yield stage $\rightarrow$ Strain-strengthening & $60-90 \mathrm{kN}$ \\
III & $104.26-133.72 \mathrm{kN}$ & stage & 105 and $120 \mathrm{kN}$ \\
VI & $>133.72 \mathrm{kN}$ & Yield stage $\rightarrow$ Strain-strengthening stage & 135 and $150 \mathrm{kN}$ \\
\hline
\end{tabular}

The variation law of the working resistance curve at the roadway corner and in the middle of the roadway side is essentially the same in each stage. In the elastic stage, the working resistance exhibits a nonlinear monotonic increasing trend, and the growth rate increases with the anchorage length. The results show that 
when the bolt is in the elastic stage, the working resistance can be greatly improved by increasing the anchorage length. In the yield stage, the working resistance of the bolt does not change. In the strainstrengthening stage, the working resistance first increases and then decreases. When the anchorage length is $2.3 \mathrm{~m}$, the working resistance of the bolt reaches its maximum value. When the pretension is not considered, the best anchorage length of the high-strength bolt at the roadway corner is $2.12 \mathrm{~m}$.
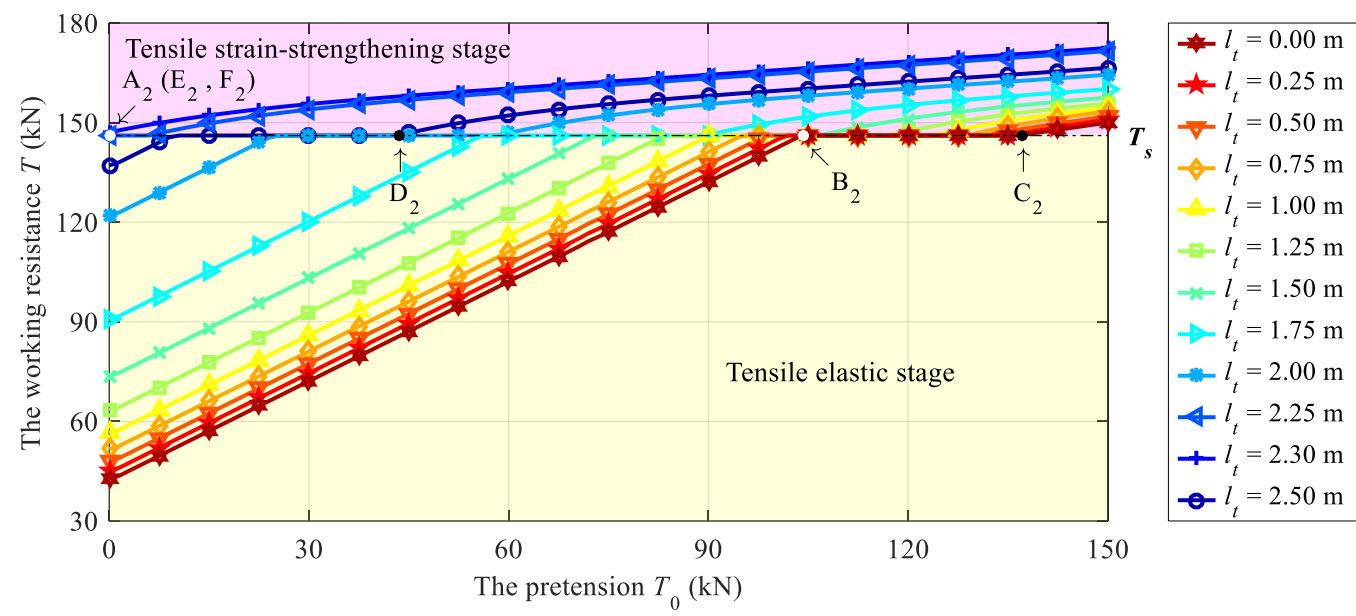

Figure 14: Curves of high-strength bolt's $T$ on corners with different $l_{t}$ values

373

374

375

376

377

378

When the anchorage length $l_{t}$ is different, the variation trend of the working resistance of the high-strength anchor bolt at the roadway corner with the increase in pretension $T_{0}$ is shown in Fig. 14. According to the change in the bolt stage with increasing pretension, the working resistance curve can be divided into three categories. After calculation, the different anchorage lengths and bolt stage changes with the increase in pretension as well as the example curves in Fig. 14 are shown in Table 7.

Table 7: High-strength bolt's $T$-curve classification with different anchorage lengths at the roadway corner

\begin{tabular}{cccc}
\hline $\begin{array}{c}\text { Curve } \\
\text { categories }\end{array}$ & Anchorage lengths & Stage of bolts with different pretensions & Examples \\
\hline I & $0-2.12 \mathrm{~m}$ & Elastic stage $\rightarrow$ Yield stage $\rightarrow$ Strain-strengthening & $0-2.00 \mathrm{~m}$ \\
& $2.12-2.28 \mathrm{~m}$ and & stage & $2.25 \mathrm{~m}$ and 2.50 \\
II & $2.38-2.50 \mathrm{~m}$ & Yield stage $\rightarrow$ Strain-strengthening stage & $\mathrm{m}$ \\
III & $2.28-2.38 \mathrm{~m}$ & Strain-strengthening stage & $2.30 \mathrm{~m}$ \\
\hline
\end{tabular}

Fig. 14 shows that in the different stages, the variation law of the working resistance at the roadway corner and in the middle of the roadway side is the same. After calculation, in the elastic stage, the slope and growth rate of the working resistance of the bolt in the roadway corner is mostly the same as that of the bolt in the middle of the roadway side. Compared with Figs. 11 and 14, it can be seen that when the combination of pretension and anchorage length is the same, the working resistance of the bolt at the roadway corner is smaller than that in the middle of the roadway side. When the anchorage length is not considered, the best pretension at the roadway corner is $104.26 \mathrm{kN}$.

Under the combination of the different pretensions $T_{0}$ and anchorage lengths $l_{t}$, the stage of the highstrength bolt at the roadway corner is shown in Fig. 15. Concurrently, the positions of the working resistance curves of different types are indicated in Fig. 15. It can be seen from Fig. 16 that the best combination curve at the roadway corner is different from that in the middle of the roadway side. The best combination curve at the roadway corner is an arc shape, and that of the bolt in the middle of the roadway side is approximately a straight line. 


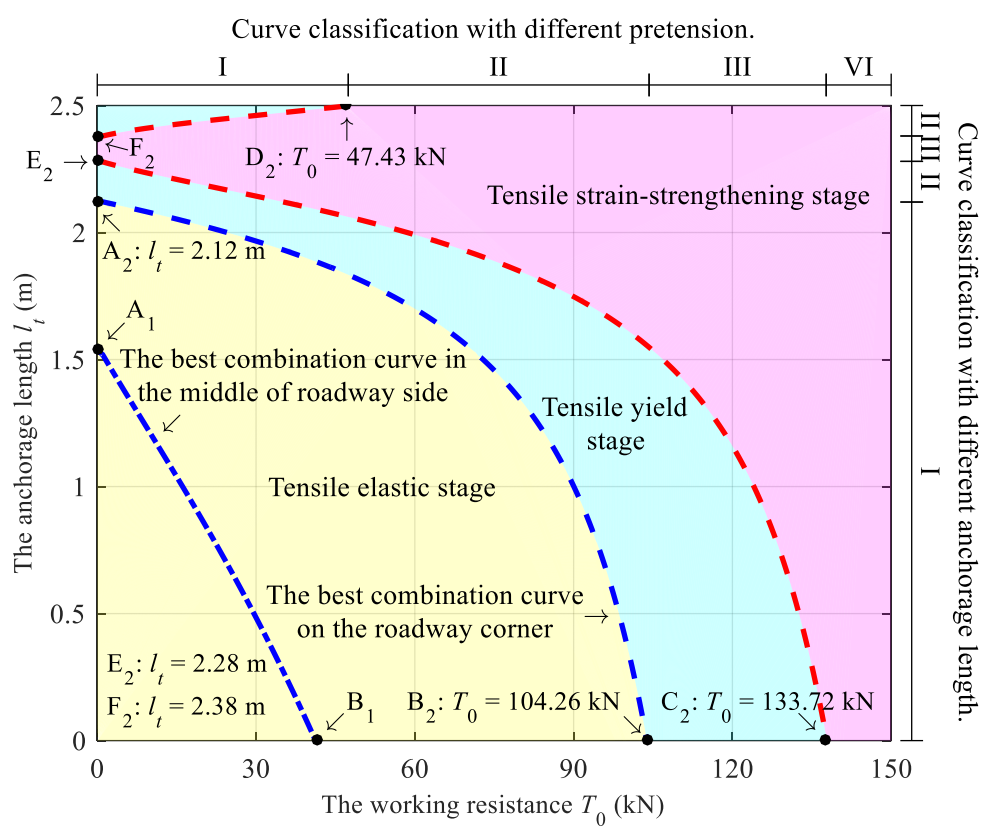

Figure 15: High-strength bolt stages under different combinations of $T_{0}$ and $l_{t}$ on corners

\section{$394 \quad 3.4$ Evolution law of the working resistance of the ordinary bolt}

395 By changing the constitutive model and taking the bolt in the middle of the roadway side as an example, the influence of the pretension $T_{0}$ and the anchorage length $l_{t}$ on the ordinary bolt is analyzed. The variation curve of the working resistance with increasing anchorage length $l_{t}$ under different pretension $T_{0}$ values is obtained, and the variation curve of the working resistance of the ordinary bolt and the high-strength bolt is shown in Fig. 16. Under the condition of different anchorage length $l_{t}$ values, the variation curve of the working resistance with increasing pretension $T_{0}$ is obtained, and the curve of the working resistance of the ordinary bolt and the high-strength bolt with increasing pretension is shown in Fig. 17. The best combination curve of the pretension and anchorage length of the ordinary anchor bolt in the middle of the roadway side and at the roadway corner is shown in Fig. 18.
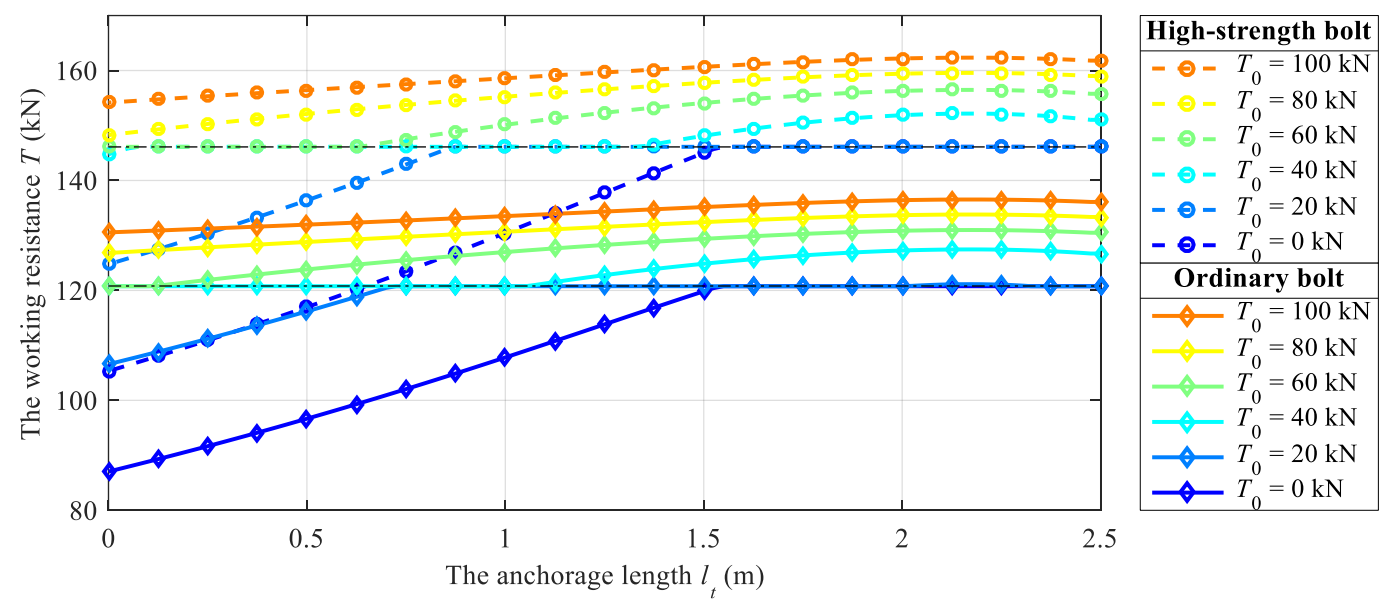


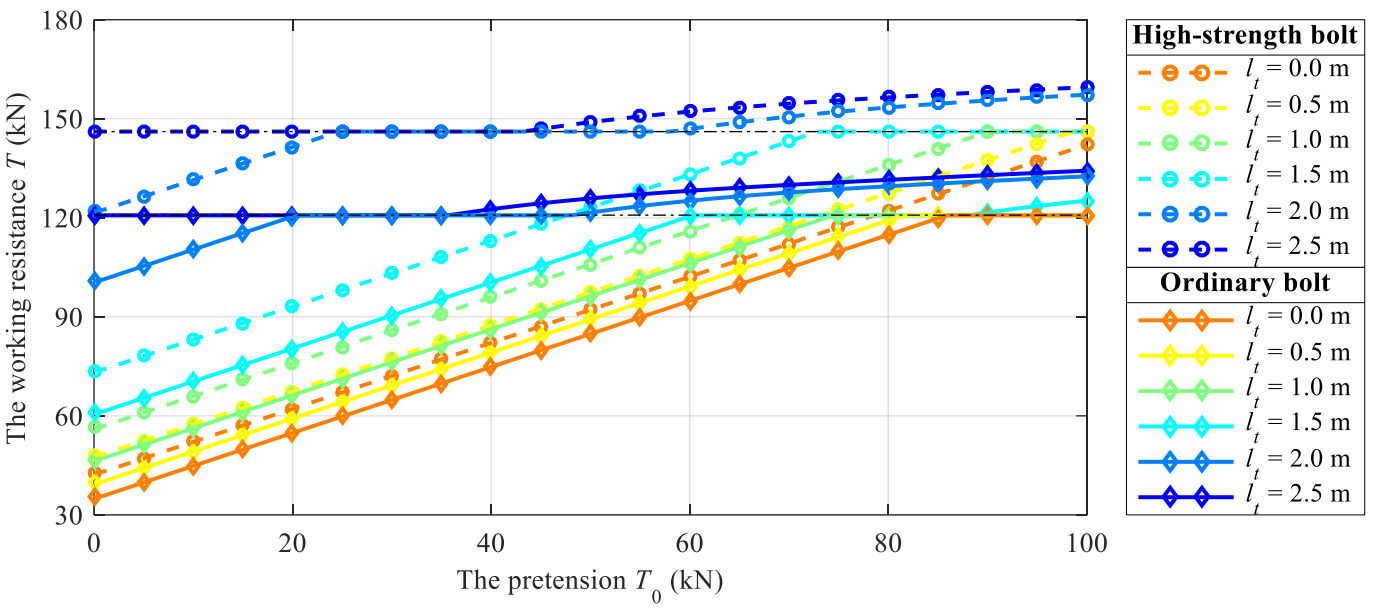

Figure 17: Curves of the ordinary bolt's $T$ in the middle of roadway side with different $l_{t}$ values

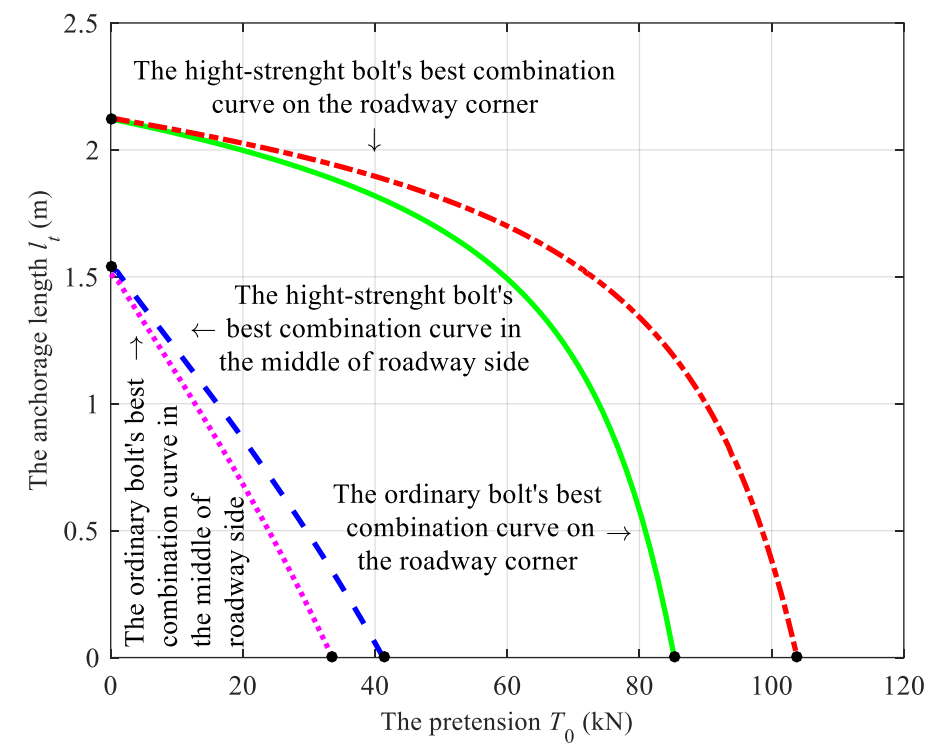

Figure 18: Ordinary bolt's best combination curves of $T_{0}$ and $l_{t}$

410 It can be seen from Figs. 16 and 17 that the influence of pretension and anchorage length on the ordinary 411 and high-strength bolts is similar. Under the same conditions, the working resistance of the ordinary bolt is 412 approximately $25 \mathrm{kN}$ less than that of the high-strength bolt. Additionally, Fig. 18 shows that the best 413 combination curve shape of the ordinary and high-strength bolts is the same, that of the bolt in the middle of 414 the roadway side is approximately a straight line, and that of the bolt at the roadway corner is a circular arc. 415 The best anchorage length for the ordinary and high-strength bolt is the same, the bolt in the middle of the 416 roadway side is $1.54 \mathrm{~m}$, and the bolt in the roadway corner is $2.12 \mathrm{~m}$. The best pretension for the ordinary 417 bolt is less than that of the high-strength bolt. The best pretension of the ordinary bolt in the middle of the 418 roadway side is $33.51 \mathrm{kN}$, and that of the ordinary bolt in the roadway corner is $85.12 \mathrm{kN}$.

\section{Conclusions}

420 To study the influence of pretension and anchorage length on the working resistance of the rock bolt, a mechanical model for calculating the working resistance is proposed based on the tensile characteristics of the rock bolt. The analytical solution of the mechanical model is obtained using the complex function method. 
The influence of pretension and anchorage length on the working resistance of the ordinary bolt and the high-strength bolt in different parts of the roadway is analyzed. The conclusions are as follows:

425

(1) Based on the tensile curve of the bolt, the constitutive model of the bolt is determined and then the mechanical model for calculating the working resistance is established, combined with the displacement distribution law of the mining roadway surrounding rock. The model can comprehensively reflect the influence of pretension, anchorage length, roadway section shape, surrounding rock deformation, and surrounding rock lithology on the bolt working resistance.

(2) When the bolt is in the elastic stage, increasing pretension and anchorage length can effectively improve the working resistance. After the bolt enters the yield and strain-strengthening stages, the working resistance cannot be effectively improved by increasing the pretension and anchorage length. When pretension is not considered, the best anchorage length for the high-strength bolt in the middle of the roadway side and in the roadway corner is 1.54 and $2.12 \mathrm{~m}$, respectively. When the anchorage length is not considered, the best pretension is 41.55 and $104.26 \mathrm{kN}$, respectively.

(3) The influence of pretension and anchorage length on the ordinary and high-strength bolts is similar. When the pretension and anchorage length are similar, the working resistance of the ordinary anchor is approximately $25 \mathrm{kN}$ less than that of the high-strength bolt. Moreover, the best anchorage length of the ordinary bolt is the same as that of the high-strength bolt. When the anchorage length is not considered, the best pretensions for the ordinary bolt in the middle of the roadway side and in the roadway corner are 33.51 and $85.12 \mathrm{kN}$, respectively.

\section{Data Availability}

The data used to support the findings of this study are available from the corresponding author upon request.

\section{Conflicts of Interest}

The authors declare no conflicts of interest.

\section{Acknowledgments}

This work was supported by the National Natural Science Foundation of China (Nos. 51774009 and 51874006), Key Research and Development Projects in Anhui Province (No. 202004a07020045), Colleges and Universities Natural Science Foundation of Anhui (No. KJ2019A0134), Anhui Provincial Natural Science Foundation (No. 2008085ME147), and the Anhui University of Technology and Science Graduate Innovation Foundation (No. 2019CX2007).

\section{References}

[1] X. Wang, W. Xie, J. Bai, S. Jing, Z. Su, and Q. Tang, "Control effects of pretensioned partially encapsulated resin bolting with mesh systems on extremely soft coal gateways: a large-scale experimental study," Rock Mechanics and Rock Engineering, vol. 53, no. 8, pp. 3447-3469, 2020.

[2] Naj Aziz, Haleh Rasekh, Ali Mirzaghorbanali, G. Yang, Saman Khaleghparast and Jan Nemcik, "An experimental study on the shear performance of fully encapsulated cable bolts in single shear test," Rock Mechanics and Rock Engineering, vol. 51, no. 7, pp. 2207-2221, 2018.

[3] S. Ma, Z. Zhao, and J. Shang, "An experimental study on the shear performance of fully encapsulated cable bolts in single shear test," Rock Mechanics and Rock Engineering, vol. 51, no. 7, pp. 2207-2221, 2018.

[4] Sedef Kocakaplan and John L. Tassoulas, "Torsional response of pretensioned elastic rods," International Journal of Solids and Structures, vol. 191-192, pp. 1-7, 2020.

[5] Hossein Jalalifar, Naj Aziz, and Muhammad Hadi, "The effect of surface profile, rock strength and pretension load on bending behaviour of fully grouted bolts," Geotechnical and Geological Engineering, vol. 24, no. 5, pp. 1203$1227,2006$. 
[6] P. Jiang, J. Lin, B. Hu, and M. Fan, "The deformation mechanism and support methods of the water-bearing soft rock roadway," Proceedings of 2015 International Symposium - Safety and High Efficiency Mining in Coal, pp. 497509,2015

[7] X. Xu and S. Tian, "Load transfer mechanism and critical length of anchorage zone for anchor bolt," PLoS ONE, vol. 15 , no. 1, pp. 1-15, 2020.

[8] N. Che, H. Wang, and M. Jiang, "DEM investigation of rock/bolt mechanical behaviour in pull-out tests," Particuology, vol. 52, pp. 10-27, 2020.

[9] Q. Wang, R. Pan, S. C. Li, H. T. Wang, and B. Jiang, "The control effect of surrounding rock with different combinations of the bolt anchorage lengths and pre-tightening forces in underground engineering," Environmental Earth Sciences, vol. 77, no. 13, pp. 501, 2018.

[10] J. Chang, K. He, Z. Yin, W. Li, S. Li, and D. Pang, "Study on the instability characteristics and bolt support in deep mining roadways based on the surrounding rock stability index: example of pansan coal mine," Advances in Civil Engineering, vol. 2020, Article ID 8855335, 2020. https://doi.org/10.1155/2020/8855335

[11] J. Zou and P. Zhang, "Analytical model of fully grouted bolts in pull-out tests and in situ rock masses," International Journal of Rock Mechanics and Mining Sciences, vol. 113, pp. 278-294, 2019.

[12] C. Wu, X. Chen, Y. Hong, R. Xu, and D. Yu, "Experimental Investigation of the Tensile Behavior of Rock with Fully Grouted Bolts by the Direct Tensile Test," Rock Mechanics and Rock Engineering, vol. 51, no. 1, pp. 351357, 2018.

[13] N. I. Muskhelishvili, Some basic problems of the mathematical theory of elasticity, P. Noordhoff, Groningen, Holland, 4th edition, 1953, in Holland.

[14] Q. Feng, B. Jiang, Q. Zhang, and L. Wang, "Analytical elasto-plastic solution for stress and deformation of surrounding rock in cold region tunnels," Cold Regions Science and Technology, vol. 108, pp. 59-68, 2014.

[15] W. Shen, X. Wang, J. Bai, W. Li, and Y. Yu, "Rock Stress Around Noncircular Tunnel: a New Simple Mathematical Method," Advances in Applied Mathematics and Mechanics, vol. 9, no. 6, pp. 1330-1346, 2017.

[16] H. T. Manh, J. Sulem, and D. Subrin, "A Closed-Form Solution for Tunnels with Arbitrary Cross Section Excavated in Elastic Anisotropic Ground," Rock Mechanics and Rock Engineering, vol. 48, pp. 277-288, 2015.

[17] A. R. Kargar, R. Rahmannejad, and M. A. Hajabasi, "A semi-analytical elastic solution for stress field of lined noncircular tunnels at great depth using complex variable method," International Journal of Solids and Structures, vol. 51, no. 6, pp. 1475-1482, 2014.

[18] Z. Guo, X. Liu, and Z. Zhu, "Elastic solution for a deep twin tunnel's stress based on complex variable theory and the superposition principle," Journal of Engineering Research, vol. 5, no. 2, pp. 68-86, 2017.

[19] A. Nazem, M. Hossaini, H. Rahami, and R. Bolghonabadi, "Optimization of Conformal Mapping Functions used in Developing Closed-Form Solutions for Underground Structures with Conventional cross Sections," International Journal of Mining and Geo-Engineering, vol. 49, no. 1, pp. 93-102, 2015.

[20] N. V. Challis, D. M. Burley, "A Numerical Method for Conformal Mapping," IMA Journal of Numerical Analysis, vol. 2, no. 2, pp. 169-181, 1982.

[21] T. K. DeLillo, A. R. Elcrat, J. A. Pfaltzgraff, "Numerical conformal mapping methods based on Faber series," Journal of Computational and Applied Mathematics, vol. 83, no. 2, pp. 205-236 1997.

[22] A. Gopal and L. N. Trefethen, "Representation of conformal maps by rational functions," Numerische Mathematik, vol. 142, no. 2, pp. 359-382, 2019.

[23] M. M. S. Nasser and F. A. A. Al-Shihri, "A Fast Boundary Integral Equation Method for Conformal Mapping of Multiply Connected Regions," SIAM Journal of Scientific Computing, vol. 35, no. 3, pp. A1736-A1760, 2013.

[24] K. Amano, D. Okano, H. Ogata, and M. Sugihara, "Numerical conformal mappings onto the linear slit domain," Japan journal of industrial and applied mathematics, vol. 29, no. 2, pp. 165-186, 2012. 